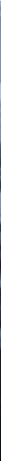

\title{
TIEMPO DE REFORMAS ¿O NO?
}

El mes de marzo de 2021 ha sido el aniversario oficial de la pandemia en nuestro país. Un año que nos sirve, a su vez, como referencia, para determinar el período transcurrido desde que se paralizó el diálogo social encaminado a reformar la reforma de 2012.

Una contrarreforma que se había planteado según una hoja de ruta con modificaciones inminentes, a medio y a largo plazo. Pero siempre bajo un mismo eslogan: "acabar con los aspectos más lesivos" de aquella. Y la vía era la derogación de lo regulado entonces.

Ya entonces nos planteábamos tres cuestiones distintas:

- ¿cuáles se consideraban los aspectos más lesivos de la reforma de 2012?

- si se derogaba la legislación de 2012 ¿con qué nos quedábamos? ¿con la de 2010, o también se alcanzaría ésta?

- ¿se conseguiría con acuerdo entre los agentes sociales?

Los interrogantes siguen siendo los mismos en algún caso y, en otros, las respuestas.

Comenzando por el orden en el que se han planteado, la primera reflexión era la siguiente: en una reforma que tiene una finalidad flexibilizadora, de adaptabilidad a las necesidades económicas y empresariales, para responder a una situación de crisis como la que se vive cuando se aprueba el RDL 3/2012 y posteriormente la Ley 3/2012, necesariamente se tiene que corresponder con una visión menos social. Y este dato es absolutamente trascendente.

De un lado, no se entra a valorar si la reforma trajo resultados más o menos acertados para el empleo en lo cuantitativo, pero en lo cualitativo, es cierto que, con determinadas instituciones, supone una rebaja de derechos respecto a los trabajadores o más bien, que posibilita esa rebaja de derechos. Y es que se sigue la línea desreguladora de flexibilización que ya es tradicional, pero que no se aparta tampoco de la reforma efectuada en 2010.

De otro lado, hemos de señalar que, esa argumentación de la crisis lo puede todo. Y ya sabemos que de un tiempo a esta parte, más que nunca, el Derecho del Trabajo es el Derecho de la crisis. En ese sentido, decíamos antes que era transcendente este dato, pero lo es porque servía como razonamiento de aquella reforma y porque da la impresión de que hoy también marcará los tiempos y las formas en el nuevo proceso de diálogo social. Pero sobre esta cuestión volveremos más adelante para dar respuesta a la tercera de las cuestiones planteadas.

Por último, con relación a la primera interrogante, para mí sigue siendo la incógnita más difícil de resolver. Y ello atendiendo a varios parámetros. Y es que, al margen, como hemos hecho, de reco- 
nocer que, efectivamente, introducía elementos que desfavorecían a los trabajadores, lo realmente complejo es concretar cuáles son los elementos que merecen la calificación de "más lesivos "de la reforma laboral de 2012. Primera dificultad: el documento programático de la Coalición de Gobierno no resulta clarificador en este sentido. No es que no se entienda su sentido, es que no aclara, de manera concreta, cuáles son aquellos aspectos que reconoce como más lesivos a pesar de que enumera una serie de instituciones a modificar.

Pero, por una parte, se alude a una serie de ellas que no son fruto de la reforma laboral del año 2012. Pongamos algún ejemplo claro: el despido por absentismo, no es resultado de esa reforma (aunque se retocó en la misma: "más lesivo" en su redacción por el RDL 3/2012 y suavizado por la Ley 3/2012), sino una institución que ya se había convertido en clásica. Y aquí, no entramos tampoco a discutir si era mejor o peor, pero lo que no puede hacerse es calificarse como lo que no es y no era, estrictamente, una institución de la reforma del 2012 —vid. diversos estudios de Gómez Salado al respecto, entre otros, "El absentismo laboral como causa del despido objetivo: puntos críticos en la redacción del artículo 52 D) del Estatuto de los Trabajadores"-. Cuestión distinta es que nos parezca o no acertada su derogación o cambio. Además, dada la escasa incidencia de su uso -aunque ello no debe medirse en términos estrictamente cuantitativos ni mucho menos-, no parece que sea uno de los aspectos más lesivos — desde luego de la reforma de 2012 no era-, más aún si lo comparamos con un pariente cercano suyo y al que sí se puede calificar sin ambages como uno -o el que más- de los aspectos lesivos, desde el punto de vista social, de la reforma laboral de 2012: la regulación del despido colectivo. E incluso otros aspectos relativos a la extinción. Pero la trascendencia y la utilización de los EREs, tanto la que ha tenido desde entonces como la que se augura que va a tener, lo sitúan en un primer escalafón. Sin embargo, en ningún documento se identifica como uno de los elementos a modificar por esta contrarreforma.

Y sí aparecen, por el contrario, como los de la primera andanada los relativos a la negociación colectiva. Instrumentos que sí se pueden interpretar como menos favorables para los trabajadores en sus actuales términos respecto regulaciones anteriores, pero a lo que debemos introducir matices. En primer término, nada tenemos que decir respecto al denominado descuelgue convencional. Su redacción en 2012 es, en los términos que se utilizan, más lesivo desde el punto de vista social. Pero, cuando se habla de la prioridad aplicativa de los convenios de empresa - que están provocando, eso sí, prácticas no recomendables como la conocida como "reclamación de las Kellys" (camareras de piso en régimen de externalización) - , con una utilización menos frecuente que la que se le presuponía - fruto, sin duda, de que entre los negociadores pueden coincidir organizaciones que ya están en el ámbito sectorial y actúan como parapeto-, no debemos obviar que su regulación es resultado, esencialmente de la reforma de 2011 (Real Decreto-ley 7/2011, de 10 de junio), aunque con la diferencia esencial de que entonces dependía de lo que pudieran decir los Acuerdos Marco. Y este dato es muy importante, porque a la par de señalar de que es fruto de una reforma anterior, derogar la reforma de 2012, no eliminaría esta figura ni esta posibilidad. Por último, para no extender demasiado estas reflexiones, podríamos referirnos a la ultraactividad, pero esto sería iniciar un artículo nuevo y exclusivo para ello. Solo advertir una cosa: esto de la ultraactividad tiene mucho - no ahora, sino desde siempre - de "bombo y platillo" y ello por varios motivos: a) porque lo previsto en la ley tiene carácter supletorio a lo que se pacte en la negociación colectiva; b) porque la ultraactividad es una 
institución extraordinaria que mantiene la vigencia de un convenio en tanto está abierto el proceso de negociación, de manera que, si éste decae, decae también la aplicación del convenio extendido temporalmente, de manera que la doctrina judicial anterior a la propia reforma laboral de 2012 ya planteaba como solución la aplicación del convenio colectivo de ámbito superior -es especialmente interesante, por recoger la solución que se plantea respecto a la normativa anterior a la reforma laboral del año 2012, la STS de 20 junio 2012 (RJ\2012/6844), que distingue dos posibilidades: el acuerdo entre las partes para la aplicación de un convenio colectivo de ámbito superior o, en su defecto, la aplicación automática del mismo cuando se agota el proceso negocial y no es posible el acuerdo final (a la misma solución llega también la STS de 10 diciembre 2012 [RJ\2013/1754])—.

Que hay que hacer cambios respecto a la ultraactividad, no se puede estar más de acuerdo, porque hay situaciones que no están previstas por el legislador - p. ej. si no hay convenio colectivo de ámbito superior-, o que es mejorable, pero no podemos coincidir en que sea uno de los aspectos más lesivos de la reforma laboral de 2012, no en esos términos literales.

Al margen de estas medidas se incluyen, en los diferentes documentos, referencias a la prioridad que tiene realizar cambios sobre las Modificaciones Sustanciales de las Condiciones de Trabajo (MSCT) o los efectos de la subcontratación del art. 42 ET, pero atribuir todo ello a la reforma de 2012 es darle a ésta una dimensión aún mayor de la que ya tuvo.

Y ello nos permite enlazar con la siguiente de las cuestiones que se planteaban. La relativa a la posible derogación de la reiterada reforma de 2012. A la par de que no es técnicamente sostenible - por las disfunciones que se generarían-, tampoco se conseguiría el efecto que se publicita, por cuanto que la última reforma laboral es el resultado de un proceso flexibilizador que se intensificó especialmente en 2010, 2011 y 2012 (de hecho, en el 2011 se hicieron los cambios más relevantes en la negociación colectiva en más de 30 años). Y es que, parte de las instituciones que se pretenden modificar o eliminar, como hemos afirmado, no son obra de la última reforma o ésta sólo los retoca. Por ejemplo, ¿qué hacemos con las MSCT y con la subcontratación?

Esta realidad se refleja en la diferencia de planteamientos entre los Ministerios que tienen competencia en esta materia.

Conocidos son algunos desencuentros entre ministros en el Gobierno de coalición por distintas cuestiones - algunas de índole social-y aquí, de momento, respecto al enfoque de la reforma, hay discrepancias claras entre los Ministerios de Economía y de Trabajo.

Así, frente a una postura más beligerante frente a la normativa vigente de la ministra Yolanda Díaz, existe una más moderada por parte de la ministra Calviño. Ésta última, de hecho, coincidiendo en determinados cambios propuestos como más urgentes con su compañera de gabinete, quizás mirando más a Europa, plantea una nueva reforma "sin mirar al pasado" y que responda a las necesidades de la España de hoy. En este contexto, coinciden en señalar un horizonte de un nuevo Estatuto de los Trabajadores del siglo XXI, pero, de momento, no tienen la misma hoja de ruta.

Sea como sea, se tiene el convencimiento de realizar una reforma que esté basada en el diálogo social (tercer interrogante). Idea que, sin duda, es de extraordinario interés en la situación en la que nos encontramos. Pero idea que, al mismo tiempo, requiere un consenso interno en el Gobierno. Siendo 
este el primer paso, puede entenderse que, a pesar de las dificultades, podría resultar más fácil que conseguir el acuerdo entre los agentes sociales. No porque no existan precedentes en los últimos tiempos (SMI), sino porque en las circunstancias actuales de crisis y pandemia todo es más complejo.

De hecho, el primer desencuentro ya se ha producido y mientras sindicatos y Ministerio de Trabajo quiere dar continuidad a lo que ya se avanzó hace un año, relativo a la negociación colectiva, la patronal alega que las circunstancias son extraordinarias y son las que deben modular el desarrollo del diálogo social y los eventuales acuerdos de reforma laboral. Y más aún, si la reforma laboral flexibilizaba a favor de las empresas para hacer frente a una crisis, no quiere renunciar a instrumentos que consideran útiles para ellos cuando otra crisis de dimensiones todavía no cuantificada, parece que no remite.

Pasados 9 años desde aquella controvertida reforma laboral de 2012, con sus virtudes y defectos alegados por diferentes partes, con las críticas y reflexiones doctrinales sobre la misma, existe el convencimiento de la necesidad de cambios respecto no solo aquella, sino de nuestra normativa laboral. Pero... ¿Cómo se va a hacer? ¿Cuál va a ser su alcance? ¿es el momento idóneo? ¿se conseguirá hacer por consenso? Estaremos atentos, los próximos meses serán muy interesantes...

Francisco Vila Tierno Catedrático de Derecho del Trabajo y de la Seguridad Social

Universidad de Málaga

Esta revista se conforma en el marco de las siguientes acciones investigadoras:

- Proyecto de Investigación en Programa Estatal de I+D+i «Retos Investigación» Orientada a los Retos de la Sociedad, RTI2018-094696-B-I00, titulado RETOS, REFORMAS Y FINANCIACION DEL SISTEMA DE PENSIONES: ¿SOSTENIBILIDAD VERSUS SUFICIENCIA?

- Proyecto P18-RT-2585 "Los mayores en el contexto del empleo y la protección social: un reto para el crecimiento y desarrollo económico. Un análisis de la realidad andaluza"; concesión de ayudas a proyectos de I+D+i, destinadas a las universidades y entidades públicas de investigación calificadas como agentes del Sistema Andaluz del Conocimiento, en el ámbito del Plan Andaluz de Investigación, Desarrollo e Innovación (PAIDI 2020). Convocatoria 2018

- Proyecto de Investigación "LAS NUEVAS TECNOLOGÍAS Y EL IMPACTO EN EL ÁMBITO LABORAL Y DE LA SEGURIDAD SOCIAL: EL IMPACTO SOCIO-ECONÓMICO DE LA ECONOMÍA DIGITAL", del Programa de Investigación de la Junta de Andalucía, con financiación con fondos FEDER, Ref. UMA18 FEDERJA 028

- Grupo de Investigación de la Junta de Andalucía (SEJ 347), Políticas de Empleo, Igualdad e Inserción social (PAIDI) 